Acta Crystallographica Section D

Biological

Crystallography

ISSN 0907-4449

\section{To scavenge or not to scavenge: that is the question}

Analysis of a series of diffraction data sets measured from four native as well as four nicotinic acid-soaked crystals of trypsin at $100 \mathrm{~K}$ shows a high variability in radiation-sensitivity among individual crystals for both nicotinic acid-soaked and native crystals. The level of radiation-sensitivity and the extent of its variability is statistically indistinguishable between the two conditions. This suggests that this potential scavenger does not have any statistically significant effect on the amount of radiation damage incurred in the crystals on X-ray irradiation. This is in contrast to previous results [Kauffmann et al. (2006), Structure, 14, 1099-1105] where only one crystal specimen was used for each condition (native and nicotinic acid-soaked).

\section{Introduction}

Radiation damage to macromolecular crystals incurred by exposure to X-rays during diffraction data collection was a curse in the first decades of protein crystallography when experiments were performed at ambient temperature. The introduction of cryocooling of crystals largely alleviated this problem, but it re-emerged after crystallographers started using very bright beamlines at thirdgeneration synchrotrons. Even at $100 \mathrm{~K}$, protein and nucleic acid crystals undergo specific damage at individual sites within a macromolecule as well as nonspecific damage, resulting in an overall loss of diffracted intensities. In fact, the non-isomorphism caused by severe radiation-damage effects may completely obscure the intrinsically small anomalous diffraction phasing signals required for the solution of novel crystal structures. The primary radiation damage resulting from absorption of an X-ray photon and subsequent ejection of a photoelectron cannot be significantly influenced by modification of the diffraction experiment. However, the secondary effects caused by somewhat mobile electrons and/or radicals generated by the photoelectrons can, at least in part, be affected by changing the experimental conditions.

One of the possible ways of mitigating secondary radiation damage is the use of radioprotecting scavengers that neutralize mobile species such as electrons, protons or radicals within cryocooled crystalline samples, as well as other larger species at ambient temperatures. The effects of several possible scavengers have been investigated by means of UV and EPR spectroscopy (Beitlich et al., 2007; SouthworthDavies \& Garman, 2007; Macedo et al., 2009) and by crystallographic analysis (Zaloga \& Sarma, 1974; Sarma \& Zaloga, 1975; Murray \& Garman, 2002; Kauffmann et al., 2006; Barker et al., 2009; Macedo et $a l ., 2009)$ at both room and cryo temperatures. Among several tested scavengers identified as potentially the most promising were ascorbic acid (Murray \& Garman, 2002; Southworth-Davies \& Garman, 2007; Barker et al., 2009), nicotinic acid (Kauffmann et al., 2006) and benzoquinone (Barker et al., 2009). Kauffmann et al. (2006) investigated the effect of three compounds, nicotinic acid, glutathione and DTNB (5,5'-dithio-bis-2-nitrobenzoic acid), on the behavior of three protein crystals, lysozyme, thaumatin and elastase, using one crystal for each combination. Drawing generally valid conclusions from the measurement of only one sample implies the assumption that all 
Table 1

Diffraction data statistics for four native and four nicotinic acid-soaked crystals of the $P 2_{1} 2_{1} 2_{1}$ form of trypsin.

All data sets consisted of 100 images of $1^{\circ}$ rotation with resolution extending to $1.2 \AA$ and a multiplicity of 4.1 . Values in parentheses correspond to the highest resolution bin (1.24-1.20 $\mathrm{A}$ ). The absorbed dose for each data set was about $0.5 \times 10^{6} \mathrm{~Gy}$. The numerical values of unit-cell parameters and mosaicity as obtained from $H K L-2000$ obviously do not have accuracy to three decimal digits; they are shown to illustrate the tendencies of their change in successive data sets.

\begin{tabular}{|c|c|c|c|c|c|c|c|c|}
\hline \multirow{2}{*}{$\begin{array}{l}\text { Crystal } \\
\text { data set }\end{array}$} & \multicolumn{3}{|c|}{ Unit-cell parameters $(\AA ̊ \cap)$} & \multirow{2}{*}{$\begin{array}{l}\text { Mosaicity } \\
\text { range }\left({ }^{\circ}\right)\end{array}$} & \multirow[b]{2}{*}{$I / \sigma(I)$} & \multirow{2}{*}{$\begin{array}{l}R_{\text {merge }} \\
(\%)\end{array}$} & \multirow{2}{*}{$\begin{array}{l}\text { Completeness } \\
(\%)\end{array}$} & \multirow{2}{*}{$\begin{array}{l}B_{\text {Wilson }} \\
\left(\AA^{2}\right)\end{array}$} \\
\hline & $a$ & $b$ & $c$ & & & & & \\
\hline \multicolumn{9}{|c|}{ Native1, crystal size $0.1 \times 0.1 \times 0.3 \mathrm{~mm}$} \\
\hline Native1 $A$ & 54.155 & 58.356 & 66.575 & $0.138-0.207$ & $31.2(9.2)$ & $4.6(15.9)$ & $100.0(99.8)$ & 6.82 \\
\hline Native1 $B$ & 54.160 & 58.364 & 66.579 & $0.151-0.209$ & $30.6(8.5)$ & $4.6(17.7)$ & $100.0(99.8)$ & 7.06 \\
\hline Native1 $C$ & 54.164 & 58.370 & 66.582 & $0.165-0.210$ & $30.7(7.8)$ & $4.5(19.3)$ & $100.0(99.8)$ & 7.40 \\
\hline Native1 $D$ & 54.168 & 58.376 & 66.584 & $0.173-0.211$ & $30.2(7.2)$ & $4.6(21.2)$ & $100.0(99.8)$ & 7.70 \\
\hline Native1 $E$ & 54.169 & 58.382 & 66.578 & $0.179-0.212$ & $29.7(6.5)$ & $4.6(22.9)$ & $99.9(99.8)$ & 8.02 \\
\hline \multicolumn{9}{|c|}{ Native2, crystal size $0.15 \times 0.15 \times 0.4 \mathrm{~mm}$} \\
\hline Native2 $A$ & 54.275 & 58.402 & 66.324 & $0.132-0.217$ & $32.7(13.8)$ & $4.1(9.7)$ & $99.7(99.8)$ & 6.38 \\
\hline Native2 $B$ & 54.282 & 58.419 & 66.343 & 0.1330 .215 & $32.4(12.7)$ & $4.1(10.1)$ & $99.7(99.8)$ & 6.65 \\
\hline Native2 $C$ & 54.290 & 58.436 & 66.364 & $0.134-0.213$ & $32.1(11.3)$ & $4.1(11.1)$ & $99.7(99.8)$ & 6.96 \\
\hline Native2 $D$ & 54.299 & 58.452 & 66.385 & $0.141-0.218$ & $31.5(10.0)$ & $4.1(12.2)$ & $99.7(99.8)$ & 7.22 \\
\hline Native2 $E$ & 54.309 & 58.467 & 66.407 & $0.148-0.226$ & $30.9(8.6)$ & $4.1(14.1)$ & $99.8(99.8)$ & 7.58 \\
\hline \multicolumn{9}{|c|}{ Native3, crystal size $0.15 \times 0.25 \times 0.3 \mathrm{~mm}$} \\
\hline Native3 $A$ & 54.197 & 58.418 & 66.470 & $0.191-0.305$ & $28.2(8.9)$ & $4.6(14.6)$ & $100.0(100.0)$ & 7.54 \\
\hline Native3 $B$ & 54.233 & 58.466 & 66.531 & $0.195-0.316$ & $27.4(6.9)$ & $4.5(17.7)$ & $100.0(100.0)$ & 8.23 \\
\hline Native3 $C$ & 54.271 & 58.512 & 66.588 & $0.207-0.334$ & $26.2(4.9)$ & $4.7(24.3)$ & $100.0(100.0)$ & 9.03 \\
\hline Native3 $D$ & 54.317 & 58.566 & 66.653 & $0.228-0.363$ & $24.2(2.8)$ & $4.9(41.2)$ & $100.0(100.0)$ & 10.30 \\
\hline Native3 $E$ & 54.348 & 58.601 & 66.687 & $0.245-0.393$ & $22.8(1.7)$ & $5.1(60.5)$ & $99.8(98.2 .0)$ & 11.40 \\
\hline \multicolumn{9}{|c|}{ Native 4 , crystal size $0.1 \times 0.2 \times 0.4 \mathrm{~mm}$} \\
\hline Native $4 A$ & 54.191 & 58.474 & 66.265 & $0.132-0.198$ & $29.5(17.6)$ & $4.5(7.4)$ & $97.9(96.0)$ & 6.34 \\
\hline Native4 $B$ & 54.214 & 58.504 & 66.303 & $0.140-0.211$ & $29.0(14.9)$ & $4.4(8.3)$ & $97.9(95.9)$ & 6.84 \\
\hline Native4 $C$ & 54.237 & 58.531 & 66.339 & $0.152-0.228$ & $28.5(12.0)$ & $4.4(10.4)$ & $97.9(96.0)$ & 7.39 \\
\hline Native4 $D$ & 54.260 & 58.555 & 66.371 & $0.166-0.248$ & $27.9(9.1)$ & $4.5(13.5)$ & $98.0(95.9)$ & 8.04 \\
\hline Native4 $E$ & 54.284 & 58.578 & 66.398 & $0.183-0.269$ & $27.1(6.7)$ & $4.5(18.2)$ & $98.0(95.9)$ & 8.68 \\
\hline \multicolumn{9}{|c|}{$\mathrm{NicOH} 1$, crystal size $0.1 \times 0.1 \times 0.3 \mathrm{~mm}$} \\
\hline NicOH1 $A$ & 54.186 & 58.484 & 66.246 & $0.141-0.196$ & $32.4(15.2)$ & $4.0(9.1)$ & $99.4(98.3)$ & 6.42 \\
\hline NicOH1 $B$ & 54.194 & 58.494 & 66.262 & $0.146-0.196$ & $30.3(11.0)$ & $4.1(11.7)$ & $99.4(98.3)$ & 6.60 \\
\hline $\mathrm{NicOH} 1 \mathrm{C}$ & 54.198 & 58.501 & 66.272 & $0.150-0.199$ & $28.7(9.1)$ & $4.2(13.7)$ & $99.5(98.3)$ & 6.74 \\
\hline NicOH1 $D$ & 54.198 & 58.505 & 66.280 & $0.154-0.199$ & $26.8(7.2)$ & $4.4(16.7)$ & $99.5(98.3)$ & 6.82 \\
\hline NicOH1 $E$ & 54.198 & 58.508 & 66.287 & $0.159-0.200$ & $25.4(6.1)$ & $4.7(19.3)$ & $99.5(98.2)$ & 6.88 \\
\hline \multicolumn{9}{|c|}{$\mathrm{NicOH} 2$, crystal size $0.15 \times 0.15 \times 0.4 \mathrm{~mm}$} \\
\hline $\mathrm{NicOH} 2 A$ & 54.202 & 58.355 & 66.341 & $0.160-0.216$ & $33.3(15.1)$ & $4.0(9.2)$ & $98.0(96.0)$ & 7.00 \\
\hline $\mathrm{NicOH} 2 B$ & 54.211 & 58.372 & 66.361 & $0.161-0.209$ & $33.1(14.6)$ & $4.0(9.6)$ & $98.0(96.1)$ & 7.21 \\
\hline $\mathrm{NicOH} 2 \mathrm{C}$ & 54.220 & 58.389 & 66.383 & $0.163-0.205$ & $32.8(13.7)$ & $3.9(9.7)$ & $98.0(96.1)$ & 7.39 \\
\hline $\mathrm{NicOH} 2 D$ & 54.230 & 58.406 & 66.407 & $0.167-0.203$ & $32.5(12.7)$ & $3.9(10.4)$ & $98.0(96.1)$ & 7.60 \\
\hline $\mathrm{NicOH} 2 E$ & 54.239 & 58.423 & 66.429 & $0.174-0.212$ & $32.2(11.6)$ & $3.9(11.1)$ & $98.0(96.1)$ & 7.80 \\
\hline \multicolumn{9}{|c|}{$\mathrm{NicOH} 3$, crystal size $0.15 \times 0.2 \times 0.3 \mathrm{~mm}$} \\
\hline NicOH3 $A$ & 54.167 & 58.387 & 66.484 & $0.167-0.215$ & $28.6(12.0)$ & $4.5(10.5)$ & $99.9(100.0)$ & 6.76 \\
\hline NicOH3 $B$ & 54.179 & 58.423 & 66.533 & $0.186-0.254$ & $27.2(7.8)$ & $4.5(15.6)$ & $99.9(100.0)$ & 7.78 \\
\hline $\mathrm{NicOH} 3 \mathrm{C}$ & 54.186 & 58.441 & 66.568 & $0.206-0.320$ & $25.6(4.6)$ & $4.8(27.1)$ & $99.9(100.0)$ & 9.11 \\
\hline NicOH3 $D$ & 54.191 & 58.450 & 66.592 & $0.224-0.387$ & $23.8(2.6)$ & $5.3(49.0)$ & $99.9(100.0)$ & 10.78 \\
\hline NicOH3 $E$ & 54.194 & 58.452 & 66.609 & $0.238-0.457$ & $21.9(1.3)$ & $5.9(66.0)$ & $99.0(91.7)$ & 12.30 \\
\hline \multicolumn{9}{|c|}{$\mathrm{NicOH} 4$, crystal size $0.15 \times 0.2 \times 0.3 \mathrm{~mm}$} \\
\hline $\mathrm{NicOH} 4 A$ & 54.178 & 58.488 & 66.228 & $0.119-0.149$ & $28.9(16.0)$ & $4.7(8.3)$ & $97.1(94.8)$ & 6.03 \\
\hline $\mathrm{NicOH} 4 B$ & 54.208 & 58.536 & 66.290 & $0.135-0.162$ & $28.5(12.9)$ & $4.6(9.8)$ & $97.1(94.5)$ & 6.66 \\
\hline $\mathrm{NicOH} 4 \mathrm{C}$ & 54.262 & 58.631 & 66.357 & $0.156-0.177$ & $27.3(9.0)$ & $4.5(13.7)$ & $97.1(94.7)$ & 7.28 \\
\hline $\mathrm{NicOH} 4 D$ & 54.275 & 58.617 & 66.400 & $0.182-0.215$ & $25.8(5.8)$ & $4.6(21.7)$ & $97.1(94.5)$ & 8.08 \\
\hline $\mathrm{NicOH} 4 E$ & 54.304 & 58.646 & 66.443 & $0.207-0.249$ & $23.9(3.6)$ & $4.9(36.4)$ & $97.1(94.6)$ & 8.94 \\
\hline
\end{tabular}

$20 \mathrm{~s}$ in the cryosolution containing $150 \mathrm{mM}$ nicotinic acid $(\mathrm{NicOH})$ and the native crystals were kept for the same time in the cryosolution without $\mathrm{NicOH}$. The space group of the crystals used in this study was $P 2_{1} 2_{1} 2_{1}$.

All diffraction data were collected on the SER-CAT beamline 22-ID at the APS, Argonne National Laboratory, using a MAR $300 \mathrm{CCD}$ detector and a wavelength of $1.0 \AA$ A. The APS storage ring operated in topup mode, keeping the ring current at $100 \pm$ $0.5 \mathrm{~mA}$. Four native and four scavengersoaked crystals were used and five consecutive data sets were collected from each crystal. The beam intensity and exposure time were set to minimize the number of overloaded detector pixels and to maintain the total dose per full data set at about $0.5 \times 10^{6}$ Gy (as estimated by RADDOSE; Murray et al., 2004). The data were processed with $H K L-2000$ (Otwinowski \& Minor, 1997). Detailed statistics of each data set are presented in Table 1. The intensities were converted to amplitudes and Wilson $B$ factors were calculated using TRUNCATE (French \& Wilson, 1978). The $R_{\mathrm{d}}$ values (Diederichs, 2006) were calculated by a Fortran program written in-house, using the scaled intensities output by SCALEPACK in the 'no merge, original index' mode.

\section{Results and discussion}

The crystals used in the experiment had dimensions that were similar but not identical (Table 1). All crystals were oriented in the cryoloop with their largest physical dimension (along the $a$ axis) approximately parallel to the goniostat spindle axis. The beam size was collimated to $0.2 \times 0.2 \mathrm{~mm}^{2}$. The uncollimated beam profile at the collimator slits was approximately Gaussian with $0.4 \times 0.4 \mathrm{~mm}$ FWHM. Therefore, the flux density of the beam on the sample was almost uniform (top-hat beam profile). Parallel to the rotation axis, the beam size

samples behave similarly. Testing this assumption, we report here the results of an analogous investigation using four native and four nicotinic acid-soaked crystals of bovine trypsin.

\section{Experimental}

Crystals of bovine pancreatic trypsin (Sigma, Lot No. 104K7575) were grown from a 1:1 mixture of protein and well solution. The protein solution contained $30 \mathrm{mg} \mathrm{ml}^{-1}$ trypsin, $5 \mathrm{mg} \mathrm{ml}^{-1}$ benzamidine, $30 \mathrm{~m} M$ HEPES pH 7.0 and $3 \mathrm{mM} \mathrm{CaCl} 2$. The well solution contained 20\% PEG 8K, $100 \mathrm{~m} M$ cacodylate pH 6.5, $200 \mathrm{~m} M$ ammonium sulfate and $15 \%$ glycerol. For cryocooling, the crystals were cryoprotected in the well solution with $25 \%$ volume of water replaced by glycerol. The scavenger-soaked crystals were kept for was smaller than the size of the crystals. Orthogonal to the rotation axis, the beam size was comparable or slightly larger than the size of the crystals. Therefore, the fraction of the crystal volume that might have moved in and out of the beam during the rotation of $100^{\circ}$ was very small. Thus, the energy dose absorbed by the exposed volume of the crystals was very uniform both spatially as well as from frame to frame. In addition, by keeping the flux density on the sample and the exposure time the same, attempts were made to ensure that all used crystals absorbed comparable doses per data set (approximately $0.5 \mathrm{MGy}$ ). This corresponds to about $1.6 \%$ of the 'Garman limit' (Owen et al., 2006) per data set or $8 \%$ for all five data sets collected from each crystal.

As seen in Table 1, the effect of irradiation manifests itself in the form of increasing unit-cell parameters, mosaicity, $R_{\text {merge }}$ and $B_{\text {Wilson }}$ values and decreasing $I / \sigma(I)$. However, using these criteria it is 


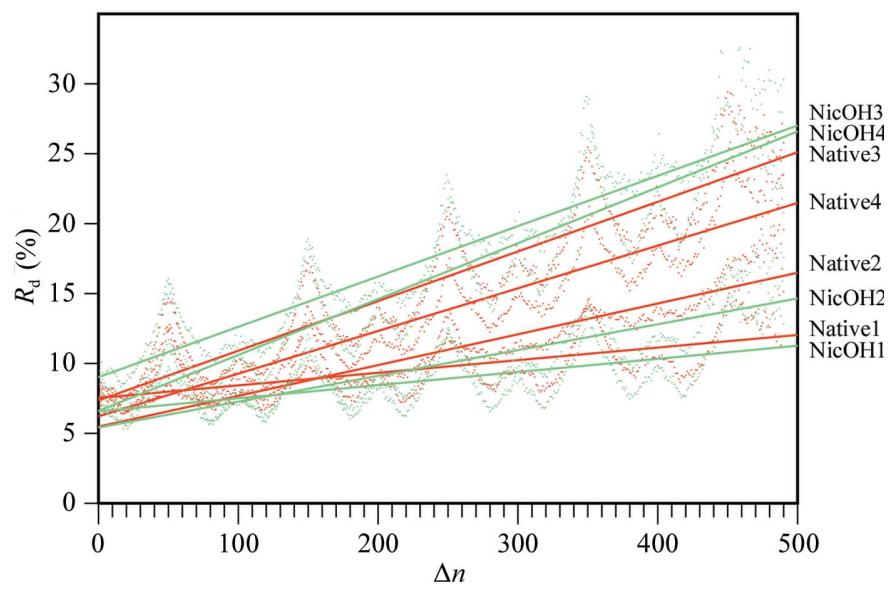

Figure 1

$R_{\mathrm{d}}$ plots for four native and four nicotinic acid-soaked crystals of trypsin. The numbers on the horizontal axis $(\Delta n)$ correspond to differences between the image numbers of a pair of reflections contributing to $R_{\mathrm{d}}$. Native crystals are represented in red; NicOH-soaked crystals are shown in green. Least-squares fitted lines for each crystal are also shown. The modulations of $R_{\mathrm{d}}$ with a period of 100 reflect the number of frames collected for each data set but is not dependent on the crystal symmetry or orientation. In contrast to Kauffmann et al. (2006), the $R_{\mathrm{d}}$ values for different crystals are not normalized to a common value of 1.0 at $\Delta n=0$ in order to better represent the differences in their diffraction qualities.

difficult to compare the behavior of different crystals. More convenient for this purpose is the $R_{\mathrm{d}}$ plot used by Sliz et al. (2003) and generalized by Diederichs (2006), where the normalized difference of intensities of pairs of symmetry-equivalent reflections is plotted as a function of the image-number difference (and therefore of the absorbed dose) between the pairs of images where these reflections occur. This plot is presented in Fig. 1 for all native and nicotinic acidsoaked crystals. It is evident that the variation among the four native crystals and among the four nicotinic acid-soaked crystals is as large as that between each of these groups of data sets. Even though all crystals had been prepared for data collection in as identical a manner as possible, the individual specimens showed varying amounts of radiation damage which was not correlated with the presence of nicotinic acid.

If one were to select only a single crystal of each type ('native unsoaked' and 'scavenger soaked'), one could easily draw the wrong conclusions owing to inadequate statistical accuracy. For example, the pair Native3 and NicOH1 would suggest that nicotinic acid may be a very successful radioprotectant, but the pair Native1 and NicOH3 would conversely suggest that soaking in this compound is highly counterproductive. It seems that the intrinsic variation in the radiation vulnerability between otherwise similar crystals is quite large and drawing meaningful conclusions about the quality of potential scavengers requires checking several crystals to obtain sufficient statistics for meaningful results. This may explain the differences between the current results and those obtained by Kauffmann et al. (2006), where only a single native and a single soaked crystal were used for analysis. The results of the previous authors may suggest that the success of the scavenger depends on the combination of a particular scavenger with a particular protein. The current results, in which four crystals of each type were used, suggest that nicotinic acid is not a universally applicable radioprotecting scavenger.
It should be noted that four independent measurements are not sufficient for statistical accuracy. However, as can be seen from the least-squares fits in Fig. 1, the variations of $R_{\mathrm{d}}$ are so large that, although the average values for each of the two conditions might change a small amount if more than four independent measurements were carried out, the resulting change would be insignificant compared with the observed variability in the properties of individual crystals.

\section{Conclusions}

Comparison of several native and nicotinic acid-soaked crystals of trypsin has shown that the manifested damage incurred by identical absorbed doses of X-rays varies considerably between otherwise similar crystals and does not appear to depend on the presence of nicotinic acid, a potential scavenger, in the solvent. It may be concluded that meaningful analyses of the usefulness of potential radioprotective scavengers require a number of crystals that is large enough for statistical significance to be checked in order to obtain valid results, since the detailed diffraction properties of individual crystals vary considerably even if specimens of comparable size are selected from the same crystallization drop.

This work was supported in part with Federal funds from the National Cancer Institute, National Institutes of Health contract No. NO1-CO-12400 and the Intramural Research Program of the NIH, National Cancer Institute, Center for Cancer Research. The content of this publication does not necessarily reflect the views or policies of the Department of Health and Human Services, nor does the mention of trade names, commercial products or organizations imply endorsement by the US Government. Diffraction data were collected on the SER-CAT beamline 22-ID at the Advanced Photon Source, Argonne National Laboratory. Use of the Advanced Photon Source was supported by the US Department of Energy, Office of Science, Office of Basic Energy Sciences under Contract No. W-31-109-Eng38.

\section{References}

Barker, A. I., Southworth-Davies, R. J., Paithankar, K. S., Carmichael, I. \& Garman, E. F. (2009). J. Synchrotron Rad. 16, 205-216.

Beitlich, T., Kühnel, K., Schulze-Briese, C., Shoeman, R. L. \& Schlichting, I. (2007). J. Synchrotron Rad. 14, 11-23.

Diederichs, K. (2006). Acta Cryst. D62, 96-101.

French, S. \& Wilson, K. (1978). Acta Cryst. A34, 517-525.

Kauffmann, B., Weiss, M. S., Lamzin, V. S. \& Schmidt, A. (2006). Structure, 14, 1099-1105.

Macedo, S., Pechlaner, M., Schmid, W., Weik, M., Sato, K., Dennison, C. \& Djinović-Carugo, K. (2009). J. Synchrotron Rad. 16, 191-204.

Murray, J. \& Garman, E. (2002). J. Synchrotron Rad. 9, 347-354.

Murray, J. W., Garman, E. F. \& Ravelli, R. B. G. (2004). J. Appl. Cryst. 37, 513-522.

Otwinowski, Z. \& Minor, W. (1997). Methods Enzymol. 276, 307-326.

Owen, R. L., Rudiño-Piñera, E. \& Garman, E. F. (2006). Proc. Natl Acad. Sci. USA, 109, 4912-4917.

Sarma, R. \& Zaloga, G. (1975). J. Mol. Biol. 98, 479-484.

Sliz, P., Harrison, S. C. \& Rosenbaum, G. (2003). Structure, 11, 13-19.

Southworth-Davies, R. J. \& Garman, E. F. (2007). J. Synchrotron Rad. 14, 73-83.

Zaloga, G. \& Sarma, R. (1974). Nature (London), 251, 551-552. 